\title{
A CLINICIAN'S GUIDE TO X-LINKED HYPOPHOSPHATEMIA
}

\author{
Thomas O. Carpenter ${ }^{1}$, Erik A. Imel' ${ }^{2}$, Ingrid A. Holm³ ${ }^{3}$, Suzanne M. Jan de Beur ${ }^{4}$, and Karl L. \\ Insogna ${ }^{1}$ \\ ${ }^{1}$ Yale University School of Medicine, New Haven CT \\ ${ }^{2}$ Indiana University School of Medicine, Indianapolis IN \\ ${ }^{3}$ Division of Genetics, Program in Genomics, and the Manton Center for Orphan Disease \\ Research, Children's Hospital Boston and Harvard Medical School, Boston, MA \\ ${ }^{4}$ Johns Hopkins School of Medicine, Baltimore, MD
}

\begin{abstract}
$\mathrm{X}$-linked hypophosphatemia (XLH) is the prototypic disorder of renal phosphate wasting, and the most common form of heritable rickets. Physicians, patients, and XLH support groups have all expressed concerns about the dearth of information about this disease and the lack of treatment guidelines which frequently lead to missed diagnoses or mismanagement. This perspective addresses the recommendation by conferees for the dissemination of concise and accessible treatment guidelines for clinicians arising from the "Advances in Rare Bone Diseases Scientific Conference," held at the National Institutes of Health in October 2008. We briefly review the clinical and pathophysiologic features of the disorder, and offer this guide in response to the conference recommendation, base on our collective accumulated experience in the management of this complex disorder.
\end{abstract}

\section{Keywords}

Phosphate; FGF23; PHEX; rickets; osteomalacia

Physicians, patients, and support groups have expressed concern about the dearth of readily accessible treatment guidelines about X-linked hypophosphatemia (XLH). This problem has led to considerable mismanagement and missed diagnoses. Conferees at the "Advances in Rare Bone Diseases Scientific Conference," held at the National Institutes of Health in October 2008, recommended the widespread dissemination of concise, readily accessible guidelines for therapeutic approaches to XLH. As we have collectively accumulated a significant and recognized experience in the management of XLH, we offer this guide in response to the conferees' recommendations.

\footnotetext{
Corresponding author: Thomas O. Carpenter Department of Pediatrics (Endocrinology) Yale University School of Medicine 333 Cedar Street; PO Box 208064 New Haven, CT 06520-8064 Telephone: 203-785-6526 Fax: 203-737-4290

Thomas.carpenter@yale.edu. Erik A. Imel: eimel@iupui.edu Ingrid A. Holm: Ingrid.Holm@childrens.harvard.edu Suzanne M. Jan de Beur: sjandebe@jhmi.edu Karl L. Insogna: karl.insogna@yale.edu.

CONFLICTS OF INTEREST

Drs. Carpenter, Insogna, and Jan de Beur perform consulting activities for Kyowa-Hakko-Kirin Pharma, Inc., and Drs. Carpenter, Insogna, and Imel receive grant support from Kyowa-Hakko-Kirin Pharma, Inc. Dr. Holm has no conflicts of interest.

AUTHORS' CONTRIBUTIONS

All authors participated in the conception, design, writing and review of the manuscript.
} 


\section{CLINICAL PRESENTATION AND NATURAL HISTORY}

$\mathrm{XLH}$ is the prototypic disorder of renal phosphate wasting, and the most common form of heritable rickets (1). Clinical manifestations vary in severity, but patients most commonly present in childhood with bowing deformities of the legs. Progressive bowing, antero-medial rotational torsion of tibiae, and short stature represent the predominant skeletal outcomes in growing children. With medical therapy these abnormalities can be improved, but usually do not entirely resolve. Metaphyseal changes of rickets are usually evident on radiographs (we preferentially image the distal femur) when a child presents with XLH (Figure 1). Osteomalacia (accumulation of unmineralized osteoid) is characteristic of untreated XLH.

$\mathrm{XLH}$ is often misdiagnosed as nutritional rickets, metaphyseal dysplasia, and physiologic bowing. Hypophosphatemia and low-normal circulating $1,25(\mathrm{OH})_{2} \mathrm{D}$ levels are typical biochemical findings. Serum alkaline phosphatase activity is elevated in children, but not to the degree observed in rickets due to vitamin D deficiency. Serum calcium is normal, as is circulating 25-OHD. Radiographic images should exclude diagnoses of physiologic bowing and most skeletal dysplasias. As the diagnosis of XLH requires long-term medical therapy, definitive evidence of renal phosphate wasting is critical to obtain before committing patients to treatment. A 2-hr fasting urine specimen, together with a blood sample collected at the midpoint of the urine collection period is used to calculate the percent tubular reabsorption of phosphate (TRP), and to determine the tubular threshold maximum for phosphate (TMP/GFR). Dental abscesses, arthritis and calcification of tendons and ligaments (enthesopathy) often develop in later life and are discussed below. For more detailed discussion of clinical manifestations of XLH the reader is referred to several reviews (2-4)

XLH was initially referred to as "vitamin D resistant rickets" due to the lack of therapeutic response to vitamin D in dosages that would cure nutritional rickets. Subsequent recognition that renal phosphate wasting was the principal pathophysiologic abnormality led to the use of phosphate replacement regimens, which resulted in partial correction of skeletal lesions but led to hyperparathyroidism. Combining active vitamin $\mathrm{D}$ metabolites with a balanced dose of phosphate has since become the mainstay of therapy. Careful monitoring to avoid toxicity is required. Most affected children and symptomatic or severely affected adults are candidates for treatment.

\section{PATHOPHYSIOLOGY}

The basic physiologic defect in XLH is impaired proximal renal tubular reabsorption of phosphate. This defect is due to reduced expression of sodium-phosphate cotransporters (NaPi-IIa and NaPi-IIc, members of the type II sodium-phosphate symporter family) on the apical surface of proximal renal tubule cells, as demonstrated in the syngenic murine model of the disease, the Hyp mouse (5). The novel hormone, FGF23, suppresses transcription of the genes encoding NaPi-IIa and NaPi-IIc, and most patients with XLH (as well as Hyp mice) have elevated circulating levels of intact FGF23.

The genetic basis for XLH (and in Hyp mice) is loss-of-function of PHEX (Phosphate regulating gene with Homology to Endopeptidases located on the $\mathbf{X}$ chromosome) $(6,7)$. PHEX is a member of the M13 family of neutral endopeptidases, which activate or degrade peptides, is expressed in bones and teeth, and localizes to the cell surface. PHEX is expressed in late embryonic development as skeletal mineralization begins (8). FGF23 does not appear to be a physiologic substrate for PHEX and the mechanism by which PHEX disruption results in elevated circulating FGF23 levels remains unclear, however both are products of the osteocyte. Circulating FGF23 is increased in other, less frequent hypophosphatemic disorders including Autosomal Dominant Hypophosphatemic Rickets 
(due to activating mutations in FGF23) (9), and Autosomal Recessive Hypophosphatemic Rickets (due to loss-of-function mutations in another osteocytic protein, dentin matrix protein 1 (DMP1) $(10,11)$. More recently recessive mutations in ectonucleotide pyrophosphatase/phophodiesterase 1 (ENPP1), can result in FGF23 mediated phosphatewasting disorders (12). This enzyme regulates local concentrations of pyrophosphate, a potent inhibitor of mineralization; loss of function of the encoding gene also been associated with the rare disorder, generalized arterial calcification of infancy (13). Thus FGF23 mediates several inherited phosphate wasting disorders, of which XLH is the most common. In addition, ectopic production of FGF23 by mescenchymal tumors causes the paraneoplastic syndrome, Tumor-Induced Osteomalacia, an acquired variant of similar pathophysiology.

Another direct consequence of elevated FGF23 levels is the abnormally regulated vitamin D axis. FGF23 can down-regulate CYP271B (which encodes 25-OHD- $1 \alpha$-hydroxylase), and up-regulate CYP24A1 (encoding the 24-hydroxylase) (14), thereby resulting in inappropriate (low to normal) levels of $1,25(\mathrm{OH})_{2} \mathrm{D}$-- due to decreased synthesis and increased catabolism.

FGF23 acts through specific FGF receptors (FGFRs) on the basolateral surface of renal tubular cells. To transduce its signal, FGF23 must form a ternary complex with a cognate FGFR and the klotho protein (15-17). The precise downstream pathway mediating the altered expression of NaPi-II and the vitamin D hydroxylases has not been clarified.

Thus, current therapy for XLH consists of phosphate and $1,25(\mathrm{OH})_{2} \mathrm{D}$, and serves as the basis for the treatment guidelines herein. Newer therapeutic strategies based on the molecular pathogenesis of XLH are under development. For example, treatment of Hyp mice with a neutralizing antibody to FGF23 results in correction of hypophosphatemia, an increased in serum $1,25(\mathrm{OH})_{2} \mathrm{D}$ and marked improvement in skeletal abnormalities (18). Other approaches have included directing therapy toward the suppression of PTH, using the calcium sensing receptor modulator, cinacalcet (19). Hopefully such new approaches will lead to treatments with improved efficacy for this chronic and disabling disorder.

\section{TREATMENT OF CHILDREN}

\section{Medical therapy}

Calcitriol and Phosphate-Most children with XLH are treated from the time of diagnosis until growth is complete. The disease spectrum is variable -- some individuals are minimally affected even without treatment. Hypophosphatemia and low to low-normal serum $1,25(\mathrm{OH})_{2} \mathrm{D}$ levels result from increased FGF23 levels (4). Current treatment with activated vitamin $\mathrm{D}$ metabolites and phosphate salts attempts to correct these deficiencies. Both activated vitamin D (calcitriol or alfacalcidol) and phosphate are usually required (see Table 1). Calciferol is not as effective, and has higher toxicity risks. Phosphate dosages may require titration to minimize abdominal pain or diarrhea, although most tolerate target doses well. Treatment during growth partially corrects leg deformities, decreases the number of necessary surgeries, and improves adult height. Early initiation of treatment appears to optimize height outcomes (20).

Most XLH treatment studies do not consistently report weight-based dosing of calcitriol and phosphate. Reported doses vary widely, from 10-80 ng/kg/day of calcitriol, and 30-180 mg/ $\mathrm{kg} / \mathrm{day}$ of elemental phosphorus (21-28), reflecting uncertainty regarding optimal doses, and concerns regarding the side effects of nephrocalcinosis, hypercalciuria and hyperparathyroidism $(20,24)$. Liquid formulations may improve adherence and allow for more precise dosing in young children. Powders and crushed tablets may also be employed. 
We recommend a calcitriol dosage of 20 to $30 \mathrm{ng} / \mathrm{kg} /$ day in 2-3 divided doses, and an elemental phosphorus dose of 20-40 mg/kg/day (in 3-5 divided doses), acknowledging that some children require more, while some do well with less. We often titrate to the target doses over several days to weeks to minimize gastrointestinal side effects. Alternatively, some initially employ higher calcitriol doses $(50-70 \mathrm{ng} / \mathrm{kg} / \mathrm{day})$ for several months to accelerate the skeletal response, then reduce the dose to avoid hypercalciuria or hypercalcemia (23). Changes in body size, growth velocity, and skeletal mineralization will necessitate periodic dose adjustments.

Monitoring and dose adjustment-The primary goals of treatment are to correct or minimize rickets/osteomalacia, radiographic abnormalities, and skeletal deformities. A common misconception is that successful treatment requires normalization of the serum phosphate concentration, which is not a practical goal in children with XLH (29). In fact, this strategy is likely to do harm, leading to overtreatment with phosphorus and resultant secondary hyperparathyroidism. Rather, important endpoints of therapeutic efficacy include height, degree of skeletal deformity, and radiographic evidence for epiphyseal healing. Decreased height velocity or increased bowing call for reviewing adherence to treatment and dose adjustment if necessary. Maintenance of acceptable height velocity and improvement in skeletal deformities generally indicate satisfactory dosing.

To avoid complications such as hypercalcemia, hypercalciuria or hyperparathyroidism, laboratory monitoring at 3 month intervals is suggested. However, alterations in biochemical values are surrogate endpoints and may not predict skeletal response. Normophosphatemia may indicate overtreatment in some patients, and is likely to generate hyperparathyroidism. We routinely measure serum phosphate and calcium to assess possible excess dosing, serum creatinine to monitor renal function, and urinary calcium and creatinine, as hypercalciuria may occur in the absence of hypercalcemia. Hypercalcemia or hypercalciuria are indications to reduce the calcitriol dose. We obtain a random "spot" urine collection in infants and small children, and 24-hour urine collections if possible in compliant older children. Goals are to maintain a spot calcium/creatinine ratio $<0.3 \mathrm{mg} / \mathrm{mg}$ or $<4 \mathrm{mg}$ of calcium per $\mathrm{kg}$ body weight per $24 \mathrm{hrs}$.

The most useful biomarker for skeletal response is serum alkaline phosphatase activity, which is moderately elevated before treatment and decreases with treatment, serving as a surrogate marker for bone healing. Transient increases may occur when initiating therapy. PTH levels are routinely measured, as secondary hyperparathyroidism is common. Increasing PTH levels may be corrected by increasing the calcitriol dose, or by reducing the phosphate dose. The optimal amounts of these two drugs are determined by monitoring epiphyseal healing, and monitoring serum and urine calcium (Table 2).

Radiographs are indicated during the initial evaluation of XLH (Figure 1), for assessment of healing of rickets, and for evaluating skeletal deformities when considering surgical management. We routinely assess distal femoral/proximal tibial sites every 2 years to insure optimal epiphyseal correction. Radiographs are also used to evaluate focal bone pain. Technetium bone scans may be useful to evaluate suspected stress fractures.

During active therapy nephrocalcinosis may occur, independent of hypercalcemia or hypercalciuria, but related to treatment dosages (24). We suggest performing renal ultrasonography at 2-5 year intervals to detect progression of these lesions, as the finding of moderate to severe, or progressive nephrocalcinosis would warrant decreasing dosages. However, we have not encountered significant progression beyond low-grade nephrocalcinosis using the dosages described herein, and 15 year follow up of individuals with mild nephrocalcinosis has not resulted in significant clinical sequelae (30). One subject 
with moderate grade nephrocalcinosis was reported to have a mild decrease in glomerular filtration rate when actively treated, and which stabilized after discontinuation of therapy (24). Radiography and computed tomography are not recommended for monitoring this complication because of the unnecessary radiation exposure.

Growth Hormone-Growth hormone (GH) has been used as adjunctive therapy in XLH. GH and IGF-I transiently stimulate phosphate reabsorption (31) however long-term responses to GH in patients with XLH have been variable. Increases in serum phosphate and linear growth with GH treatment have been reported by some (32-36), but increased serum alkaline phosphatase activity, worsening leg deformities and radiographic rickets are reported as well. Preferential truncal growth, exacerbating the disproportion between leg length and trunk length typical of XLH may result (37). Given the lack of adequately controlled trials demonstrating improved adult height, there is no clear evidence that benefits of this therapy outweigh cost and potential side effects. Some have found selective use of GH in extremely short subjects (height Z-scores are less than -2.4) is more likely to have significant impact on final height outcomes than taller subjects (38). The authors have therefore reserved consideration of this therapy to such a population.

\section{Surgical and dental care}

The management team should include a pediatric orthopedic surgeon with experience in treating XLH. Surgery is indicated for severe bowing or tibial torsion unlikely to improve with medical management alone. Corrective osteotomies are not usually performed in children under 6 years of age, since medical therapy often improves bow deformities in this age group. Instead osteotomies are usually deferred until growth has nearly ceased, but severe deformities may require earlier therapy. Newer, less-invasive approaches include epiphysiodesis, which induces corrective differential growth of the growth plate (39).

Some children are prone to dental abscesses; one abscess predicts future abscesses. Defective dentin and microdefects in the enamel diminish the barrier between the oral environment and the pulp chamber allowing increased microorganism access to the pulp chamber, and abscess formation. Rigorous dental hygiene is recommended, including brushing 2-3 times daily and regular dental hygienist visits. Some dentists have suggested sealant application. The incidence/severity of commonly encountered dental abscesses is not clearly affected by medical therapy.

\section{Expected outcomes}

With treatment, growth and skeletal deformities generally improve. Height velocity commonly increases during the initial year of therapy $(40,41)$. Leg deformities may correct spontaneously obviating the need for surgery, although this is not always the case. Despite general growth improvement during treatment, correction is limited and adult height is usually compromised. Children with XLH undergo a normal pubertal growth spurt. Postpubertal height is predicted by pre-pubertal height (42), indicating that loss of height potential generally occurs prior to puberty. Thus, initiation of therapy at early ages is recommended, and results in improved height outcomes $(20,21)$.

\section{TREATMENT OF ADULTS}

The goals of treatment in adults are to reduce pain symptoms, the extent of osteomalacia (that is, the abundance of unmineralized osteoid present in the skeleton), and/or to improve fracture healing or surgical recovery. There are limited clinical trial data that support the efficacy of conventional therapy for these indications $(22,23,26,27,43)$. The best data come from an open-label study by Sullivan et al., who showed that conventional therapy 
reduced the extent of osteomalacia in symptomatic adults as quantified by pre- and posttreatment bone biopsies (43). Symptom scores also improved with treatment. Based on these data we recommend treatment in symptomatic adults. We do not routinely perform skeletal biopsies before treatment is begun. There is currently no evidence that conventional treatment affects long-term skeletal complications of XLH such as dental disease, arthritic complications, enthesopathy or spinous ligament calcification. However, in our experience, conventional therapy does not worsen these complications either. While available data and our experience support the use of calcitriol and phosphorus as therapy in selected adults with $\mathrm{XLH}$, it is obviously cumbersome, and has a relatively low therapeutic/toxicity ratio. Careful monitoring is required and the frequent follow-up visits and laboratory sampling can be burdensome to patients, sometimes compromising compliance.

\section{Medical therapy}

Calcitriol and Phosphate-Since there is no consensus regarding indications for treatment in adults, we employ empiric criteria in deciding when therapy might be beneficial. We emphasize to patients that clinical improvement is the therapeutic goal, and if not achieved within 9-12 months treatment should probably be discontinued. For some mildly symptomatic patients, treatment is unlikely to offer much benefit. Affected adults with the following presentations are considered candidates for pharmacologic therapy:

1. Spontaneous insufficiency fractures. These fractures most often occur in the weight bearing bones of the lower extremities, especially the shaft of the femur or tibia. There is usually not an antecedent history of significant trauma or excessive use. Metatarsals can also be affected. These fractures usually present as localized pain in the region of the fracture. Radiographs demonstrate an incomplete cortical break sometimes associated with a periosteal reaction (Figure 2). If the clinical suspicion is high and radiographs are not revealing a bone scan or an MRI can be used as more sensitive methods of detection. These fractures are more likely to heal faster with therapy and sometimes do not heal whatsoever without therapy.

2. Pending orthopaedic procedures. We believe that treatment reduces recovery time and the risk of prosthetic loosening in patients undergoing joint replacement. Therapy should start 3-6 months before the planned surgery.

3. Biochemical evidence of osteomalacia. Elevated serum alkaline phosphatase activity (of bone origin) occurs infrequently in adults with XLH, and usually indicates extensive osteomalacia when present.

4. Disabling skeletal pain. In our experience, patients presenting with disabling lower extremity pain respond well to medical treatment (43), whereas low back pain is not consistently improved. Thus insufficiency fractures need to be excluded as the cause of symptoms; pain in the absence of a fracture is presumably due to osteomalacia. If primary indications for therapy are symptom-driven, we explicitly discuss the risks and benefits of therapy at each visit, and often let the patient decide whether sufficient relief has occurred to warrant continuation.

Like pediatric XLH, adults are treated with calcitriol and phosphate. Treatment is individualized for each patient depending on age, body weight, parathyroid status and renal function. As a general guide, a normocalcemic adult patient with a normal or only mildly elevated serum PTH, usually starts treatment with $0.50-0.75 \mathrm{mcg} /$ day of calcitriol in 2 divided doses. After one week, daily phosphate ( $250 \mathrm{mg}$ of elemental phosphorus) is begun, and titrated every 4 days to $750-1000 \mathrm{mg} /$ day in 3-4 divided dosages. The reason treatment with calcitriol is begun before phosphate is to reduce the risk of exacerbating pre existing secondary hyperparathyroidism or causing it to develop; this development may occur when phosphate supplementation is begun first and, at times, simultaneously. Patients with XLH 
have low to low-normal circulating levels of endogenous $1,25(\mathrm{OH})_{2}$ vitamin $\mathrm{D}$, which may partly explain why they are prone to develop secondary and even tertiary hyperparathyroidism with phosphate treatment unless it is carefully managed.

Many adults with XLH have enthesopathy (44), which does not improve with treatment. This includes paraspinal enthesopathy and spinal ligament calcification that can lead to spinal chord compression and debilitating pain. As noted, current medical management does not prevent or reverse this complication either.

Monitoring and dose adjustment-After 4-6 weeks of this regimen, serum calcium, phosphorus, creatinine, alkaline phosphatase and PTH, and 24-hour urinary excretion of calcium and creatinine are measured. If serum PTH has increased from baseline, but the serum calcium is normal and urine calcium is $\leq 3.0 \mathrm{mg} / \mathrm{kg}$ lean body weight $/ 24$ hours, the calcitriol dose is considered inadequate and increased in $0.25 \mathrm{mcg} /$ day increments every $3-4$ weeks until the serum PTH has normalized, or the urinary calcium excretion is $3.0 \mathrm{mg} / \mathrm{kg}$ lean body weight/day. In contrast if the patient is hypercalciuric and serum PTH is normal or low 4-6 weeks after a dose change, we reduce the calcitriol dose. Once providing established doses of calcitriol and phosphorus that do not cause hypercalcemia, hypercalciuria or secondary hyperparathyroidism, we repeat the above biomarkers in 6-8 weeks to ensure stability. Serum alkaline phosphatase activity may transiently rise during the first few months of therapy, during the initial healing phase of the osteomalacia.

The major risks of long-term therapy with calcitriol and phosphorus in adults with XLH are similar to those in children: hypercalcemia, hypercalciuria, nephrolithiasis, nephrocalcinosis, and potentially, chronic kidney disease. Careful monitoring is essential in order to minimize these risks. During the first year of treatment at stable doses, we repeat biochemical evaluation, every 3-4 months. Frequent monitoring in the first year is critical because the requirements for calcitriol and phosphorus may decrease abruptly as osteomalacia heals. It is important to detect this change early to avoid prolonged hypercalcemia or hypercalciuria. Beyond the first year we generally monitor treated adult patients every 6-9 months.

In patients treated exclusively in the perioperative period, we revisit the usefulness of therapy 6-9 months after the procedure and may elect to stop treatment at that time. Otherwise patients may continue treatment for years.

If significant secondary or tertiary hyperparathyroidism persists during therapy despite optimal doses of calcitriol and particularly if accompanied by a rising serum alkaline phosphatase, cinacalcet can be used to attempt to normalize PTH values. Initial doses of 30 $\mathrm{mg}$ at bedtime can be increased to $60 \mathrm{mg}$ if necessary. Patient response has been variable: some respond well and others become refractory after an initial response. We have not routinely increased the dose of cinacalcet above $60 \mathrm{mg} /$ day. Evidence of tertiary (hypercalcemic) hyperparathyroidism may require parathyroidectomy.

\section{Surgery and Dental Care}

As noted above, we generally recommend treatment for adult patients planning orthopaedic surgery. In our experience untreated patients can take 6 months to 1 year before substantial or complete healing occurs following orthopaedic surgery. We have observed that the time to healing can be shortened with treatment. Joint replacement surgery, especially knees and hips, is not uncommon in adults with XLH because of the high frequency of degenerative joint disease and enthesopathy. We have found that treatment appears to reduce the risk of prosthetic joint loosening so we recommend treatment in this setting as well. We prefer to begin therapy in untreated patients 3 to 6 months before the operation and continue it for 6-9 
months afterwards. The guidelines for initiating treatment in this setting are the same as detailed above.

Dental disease, particularly root abscess, remains a major problem in adults with XLH requiring numerous root canals and tooth extractions. Apart from good dental hygiene including regular use of dental floss, no specific therapy has been demonstrated to prevent this debilitating complication. Whether sealants will help reduce the incidence of root abscesses is currently under study.

Expected outcomes-As noted, the goals of treatment in adults are to reduce pain, the extent of osteomalacia, and/or to improve fracture healing or surgical recovery. Radiographs can be used to objectively assess healing of fractures or recovery after surgery. Visual analog pain scales can help to quantify the symptomatic response to treatment. Bone biopsies are too invasive to use routinely as a measure of therapeutic response and unfortunately there are no good non-invasive markers that allow one to quantify the extent of the osteomalacia before and after treatment. The exception is the adult with elevated serum alkaline phosphatase activity, which can be followed as a marker of therapeutic response. In such cases serum alkaline phosphatase activity can initially rise with treatment as healing proceeds before falling into the normal range.

\section{CONCLUSION}

In sum, managing XLH is complicated. Although the current standard of treatment is suboptimal, it does improve rickets, growth and osteomalacia. Treatment requires balancing the benefits of treatment with complicated monitoring and potential risks. Multiple issues must be addressed, and choices for dose adjustment may not be straightforward. Involving clinicians with experience treating XLH is often useful. More efficacious and more convenient therapies are clearly needed.

\section{Acknowledgments}

Funding Sources: We appreciate and acknowledge support from NIH 1K23AR057096 (EAI, PI) and P50 AR054086 (TOC, PI).

\section{REFERENCES}

1. Holm, IA.; Econs, MJ.; Carpenter, TO. Familial hypophosphatemia and related disorders.. In: Glorieux, FH.; Juppner, H.; Pettifor, JM., editors. Pediatric Bone: Biology \& Diseases. Academic Press; San Diego, CA, USA: 2003. p. 603-31.

2. Pettifor JM. What's new in hypophosphataemic rickets? Eur J Pediatr. 2008; 167:493-9. [PubMed: 18214537]

3. Auricchio, A.; Sabbagh, Y.; Tenenhouse, HS.; Econs, MJ. Mendelian hypophosphatemias.. In: Beaudet, AL.; Vogelstein, B.; Kinzler, KW.; Antonarakis, SE.; Ballabio, A., editors. The Online Metabolic and Molecular Basis of Inherited Disease. McGraw-Hill; New York: 2008. p. 1-171.Available at: http://www.ommbid.com/OMMBID/ the_online_metabolic_and_molecular_bases_of_inherited_disease/b/fulltext/part21/ch197.

4. Carpenter, TO.; Drezner, M. [August 31, 2010] Primary disorders of phosphate metabolism. Available at: http://endotext.org/parathyroid/parathyroid10/parathyroid10.html.

5. Tenenhouse HS, Beck L. Renal Na+-P cotransporter gene expression in X-linked Hyp and Gy mice. Kidney Int. 1996; 49:1027-32. [PubMed: 8691720]

6. Francis F, Henning S, Korn B, Reinhardt R, de Jong P, Poustka A, Lehrach H, Rowe PSN, Goulding JN, Summerfield T, Mountford R, Read AP, Popowska E, Pronicka E, Davies KE, O'Riordan JLH, Econs MJ, Nesbitt T, Drezner MK, Oudet C, Hanauer A, Strom TM, Meindl A, Lorenz B, Cagnoli 
M, Mohnike KL, Murken J, Meitinger T. A gene (PEX) with homologies to endopeptidases is mutated in patients with X-linked hypophosphatemic rickets. Nat Genet. 1995; 11:130-6. [PubMed: 7550339]

7. Beck L, Soumounou Y, Martel J, Krishnamurthy G, Gauthier C, Goodyer CG, Tenenhouse HS. Pex/ PEX tissue distribution and evidence for a deletion in the 3 ' region of the Pex gene in X-linked hypophosphatemic mice. J Clin Invest. 1997; 99:1200-9. [PubMed: 9077527]

8. Ruchon AF, Marcinkiewicz M, Siegfried G, Tenenhouse HS, DesGroseillers L, Crine P, Boileau G. Pex mRNA is localized in developing mouse osteoblasts and odontoblasts. J Histochem Cytochem. 1998; 46:459-68. [PubMed: 9524191]

9. The ADHR Consortium. Autosomal dominant hypophosphatemic rickets is associated with mutations in FGF-23. Nat Genet. 2000; 26:345-8. [PubMed: 11062477]

10. Lorenz-Depiereux B, Bastepe M, Benet-Pages A, Amyere M, Wagenstaller J, Muller-Barth U, Badenhoop K, Kaiser SM, Rittmaster RS, Shlossberg AH, Olivares JL, Loris C, Ramos FJ, Glorieux F, Vikkula M, Juppner H, Strom TM. DMP1 mutations in autosomal recessive hypophosphatemia implicate a bone matrix protein in the regulation of phosphate homeostasis. Nat Genet. 2006; 38:1248-50. [PubMed: 17033625]

11. Feng JQ, Ward LM, Liu S, Lu Y, Xie Y, Yuan B, Yu X, Rauch F, Davis SI, Zhang S, Rios H, Drezner MK, Quarles LD, Bonewald LF, White KE. Loss of DMP1 causes rickets and osteomalacia and identifies a role for osteocytes in mineral metabolism. Nat Genet. 2006; 38:1310-5. [PubMed: 17033621]

12. Levy-Litan V, Hershkowitz E, Avizov L, Leventhal N, Bercovich D, Chalifa-Caspi V, Manor E, Buriakovsky S, Hadad Y, Goding J, Parvari R. Autosomal-recessive hypophosphatemic rickets is associated with an inactivation mutation in the ENPP1 gene. Am J Hum Genet. 2010; 86:273-8. [PubMed: 20137772]

13. Rutsch F, Ruf N, Vaingankar S, Toliat MR, Suk A, Höhne W, Schauer G, Lehmann M, Roscioli T, Schnabel D, Epplen JT, Knisely A, Superti-Furga A, McGill J, Filippone M, Sinaiko AR, Vallance H, Hinrichs B, Smith W, Ferre M, Terkeltaub R, Nürnberg P. Mutations in ENPP1 are associated with 'idiopathic' infantile arterial calcification. Nat Genet. 2003; 34:379-81. [PubMed: 12881724]

14. Shimada T, Hasegawa H, Yamazaki Y, Muto T, Hino R, Takeuchi Y, Fujita T, Nakahara K, Fukumoto S, Yamashita T. FGF-23 is a potent regulator of vitamin D metabolism and phosphate homeostasis. J Bone Miner Res. 2004; 19:429-35. [PubMed: 15040831]

15. Urakawa I, Yamazaki Y, Shimada T, Iijima K, Hasegawa H, Okawa K, Fujita T, Fukumoto S, Yamashita T. Klotho converts canonical FGF receptor into a specific receptor for FGF23. Nature. 2006; 444:770-4. [PubMed: 17086194]

16. Farrow EG, White KE. Recent advances in renal phosphate handling. Nat Rev Nephrol. 2010; 6:207-17. [PubMed: 20177401]

17. Hu MC, Shi M, Zhang J, Pastor J, Nakatani T, Lanske B, Razzaque MS, Rosenblatt KP, Baum MG, Kuro-O M, Moe OW. Klotho: a novel phosphaturic substance acting as an autocrine enzyme in the renal proximal tubule. FASEB J. 2010; 24:3438-50. [PubMed: 20466874]

18. Aono Y, Yamazaki Y, Yasutake J, Kawata T, Hasegawa H, Urakawa I, Fujita T, Wada M, Yamashita T, Fukumoto S, Shimada T. Therapeutic effects of anti-FGF23 antibodies in hypophosphatemic rickets/osteomalacia. J Bone Miner Res. 2009; 24:1879-88. [PubMed: 19419316]

19. Alon US, Levy-Olomucki R, Moore WV, Stubbs J, Liu S, Quarles LD. Calcimimetics as an adjuvant treatment for familial hypophosphatemic rickets. Clin J Am Soc Nephrol. 2008; 3:658 64. [PubMed: 18256372]

20. Makitie O, Doria A, Kooh SW, Cole WG, Daneman A, Sochett E. Early treatment improves growth and biochemical and radiographic outcome in X-linked hypophosphatemic rickets. J Clin Endocrinol Metab. 2003; 88:3591-7. [PubMed: 12915641]

21. Petersen DJ, Boniface AM, Schranck FW, Rupich RC, Whyte MP. X-linked hypophosphatemic rickets: a study (with literature review) of linear growth response to calcitriol and phosphate therapy. J Bone Miner Res. 1992; 7:583-90. [PubMed: 1414477] 
22. Glorieux FH, Marie PJ, Pettifor JM, Delvin EE. Bone response to phosphate salts, ergocalciferol, and calcitriol in hypophosphatemic vitamin D-resistant rickets. N Engl J Med. 1980; 303:1023-31. [PubMed: 6252463]

23. Harrell RM, Lyles KW, Harrelson JM, Friedman NE, Drezner MK. Healing of bone disease in Xlinked hypophosphatemic rickets/osteomalacia. Induction and maintenance with phosphorus and calcitriol. J Clin Invest. 1985; 75:1858-68. [PubMed: 3839245]

24. Verge CF, Lam A, Simpson JM, Cowell CT, Howard NJ, Silink M. Effects of therapy in X-linked hypophosphatemic rickets. N Engl J Med. 1991; 325:1843-8. [PubMed: 1660098]

25. Chesney RW, Mazess RB, Rose P, Hamstra AJ, DeLuca HF, Breed AL. Long-term influence of calcitriol (1,25-dihydroxyvitamin D) and supplemental phosphate in X-linked hypophosphatemic rickets. Pediatrics. 1983; 71:559-67. [PubMed: 6300745]

26. Costa T, Marie PJ, Scriver CR, Cole DE, Reade TM, Nogrady B, Glorieux FH, Delvin EE. Xlinked hypophosphatemia: effect of calcitriol on renal handling of phosphate, serum phosphate, and bone mineralization. J Clin Endocrinol Metab. 1981; 52:463-72. [PubMed: 6893992]

27. Rasmussen H, Pechet M, Anast C, Mazur A, Gertner J, Broadus AE. Long-term treatment of familial hypophosphatemic rickets with oral phosphate and 1 alpha-hydroxyvitamin D3. J Pediatr. 1981; 99:16-25. [PubMed: 6265614]

28. Makitie O, Kooh SW, Sochett E. Prolonged high-dose phosphate treatment: a risk factor for tertiary hyperparathyroidism in X-linked hypophosphatemic rickets. Clin Endocrinol. 2003; 58:163-8.

29. Carpenter TO. New perspectives on the biology and treatment of X-linked hypophosphatemic rickets. Pediatr Clin North Am. 1997; 44:443-66. [PubMed: 9130929]

30. Kooh SW, Binet A, Daneman A. Nephrocalcinosis in X-linked hypophosphataemic rickets: Its relationship to treatment, kidney function, and growth. Clin. Invest. Med. 1994; 17:123-30. [PubMed: 8004848]

31. Patel L, Clayton PE, Brain C, Pelekouda E, Addison GM, Price DA, Mughal MZ. Acute biochemical effects of growth hormone treatment compared with conventional treatment in familial hypophosphataemic rickets. Clin Endocrinol. 1996; 44:687-96.

32. Ariceta G, Langman CB. Growth in X-linked hypophosphatemic rickets. Eur J Pediatr. 2007; 166:303-9. [PubMed: 17171343]

33. Wilson DM, Lee PD, Morris AH, Reiter EO, Gertner JM, Marcus R, Quarmby VE, Rosenfeld RG. Growth hormone therapy in hypophosphatemic rickets. Am J Dis Child. 1991; 145:1165-70. [PubMed: 1928011]

34. Makitie O, Toiviainen-Salo S, Marttinen E, Kaitila I, Sochett E, Sipila I. Metabolic control and growth during exclusive growth hormone treatment in X-linked hypophosphatemic rickets. Horm Res. 2008; 69:212-20. [PubMed: 18204268]

35. Cameron FJ, Sochett EB, Daneman A, Kooh SW. A trial of growth hormone therapy in wellcontrolled hypophosphataemic rickets. Clin Endocrinol. 1999; 50:577-82.

36. Seikaly MG, Brown R, Baum M. The effect of recombinant human growth hormone in children with X-linked hypophosphatemia. Pediatrics. 1997; 100:879-84. [PubMed: 9346990]

37. Haffner D, Wuhl E, Blum WF, Schaefer F, Mehls O. Disproportionate growth following long-term growth hormone treatment in short children with X-linked hypophosphataemia. Eur J Pediatr. 1995; 154:610-3. [PubMed: 7588957]

38. Saggese G, Baroncelli G, Bertelloni S, Perri G. Long-term growth hormone treatment in children with renal hypophosphatemic rickets: Effects on growth, mineral metabolism, and bone density. $\mathrm{J}$ Pediatr. 1995; 127:395-402. [PubMed: 7658269]

39. Novais E, Stevens PM. Hypophosphatemic rickets: the role of hemiepiphsiodesis. J Pediatr Orthop. 2006; 26:238-44. [PubMed: 16557142]

40. Tsuru N, Chan JC, Chinchilli VM. Renal hypophosphatemic rickets. Growth and mineral metabolism after treatment with calcitriol (1,25-dihydroxyvitamin D3) and phosphate supplementation. Am J Dis Child. 1987; 141:108-10. [PubMed: 3788870]

41. Chan JC, Lovinger RD, Mamunes P. Renal hypophosphatemic rickets: growth acceleration after long-term treatment with 1,25-dihydroxyvitamin-D3. Pediatrics. 1980; 66:445-54. [PubMed: 6893489] 
42. Sochett E, Doria AS, Henriques F, Kooh SW, Daneman A, Makitie O. Growth and metabolic control during puberty in girls with X-linked hypophosphataemic rickets. Horm Res. 2004; 61:252-6. [PubMed: 15031616]

43. Sullivan W, Carpenter TO, Glorieux F, Travers R, Insogna K. A prospective trial of phosphate and 1,25-dihydroxyvitamin $\mathrm{D}_{3}$ therapy on symptomatic adults with $\mathrm{X}$-linked hypophosphatemic rickets. J Clin Endocrinol Metab. 1992; 75:879-85. [PubMed: 1517380]

44. Liang G, Katz LD, Insogna KL, Carpenter TO, Macica CM. Survey of the enthesopathy of Xlinked hypophosphatemia and its characterization in Hyp mice. Calcif Tiss Int. 2009; 85:235-46. 


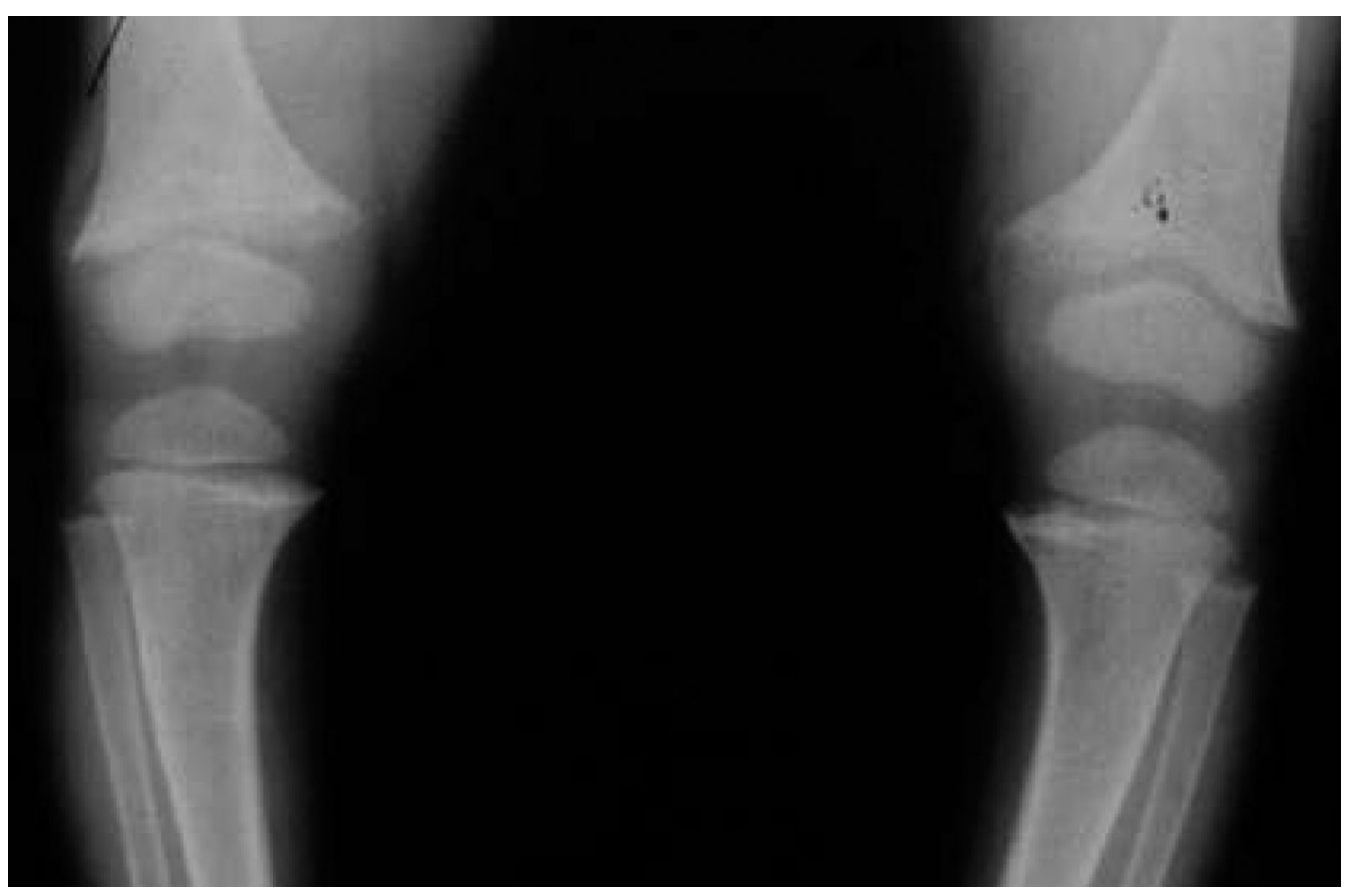

Figure 1.

Lower extremities of a 3-year-old with newly diagnosed XLH. Note the frayed and widened metaphyses of the distal femurs and proximal tibias. 


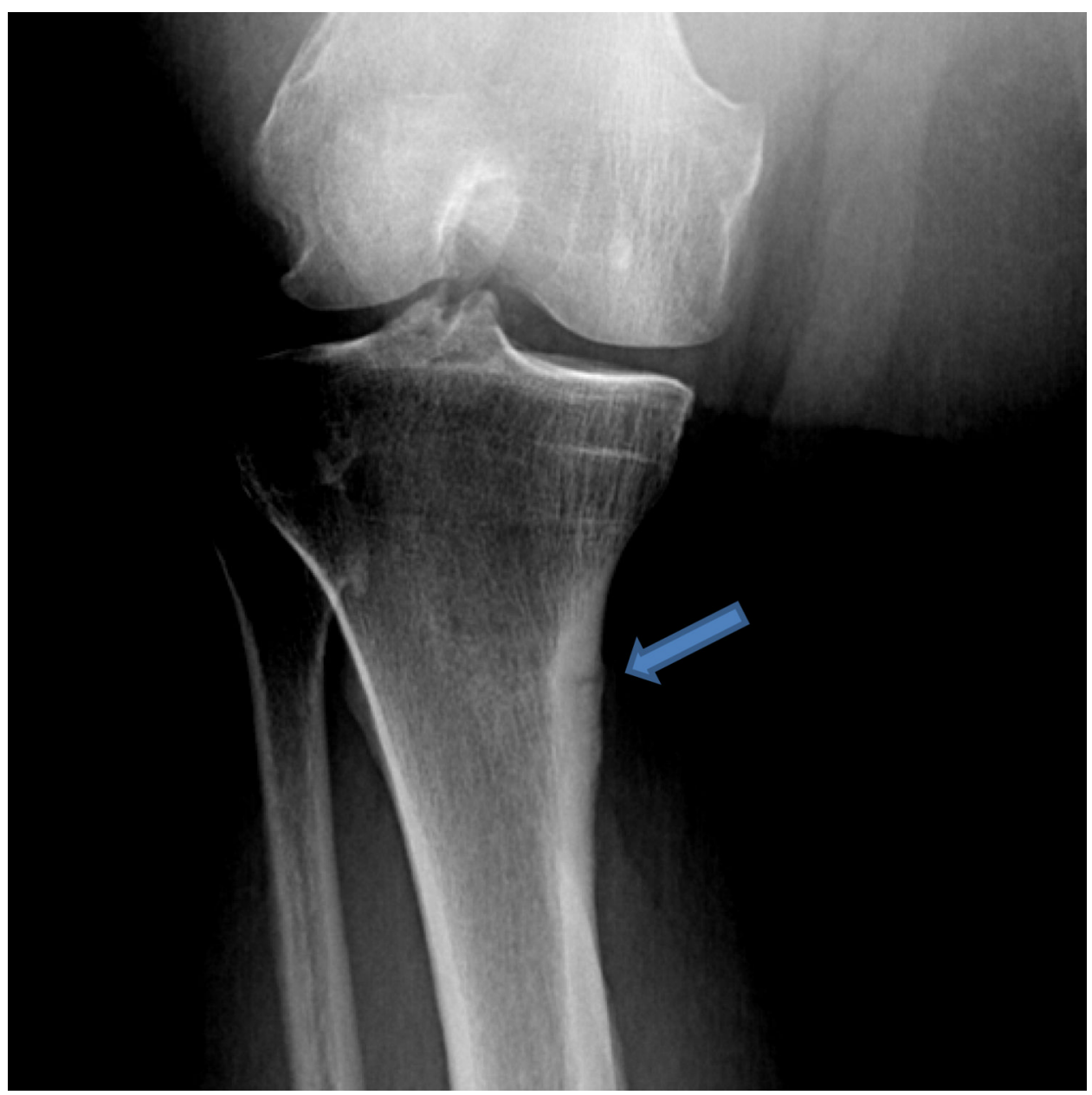

Figure 2.

An insufficiency fracture is noted in the medial aspect of the right upper tibia (arrow) in this adult patient with XLH who has not received medical therapy (calcitriol or phosphate) for a number of years. 
Table 1

Phosphate and vitamin D metabolite preparations To convert phosphorus content to millimoles, multiply by 0.32 .

\begin{tabular}{|c|c|c|c|}
\hline \multicolumn{4}{|l|}{ Phosphate Preparations } \\
\hline & Phosphorus content & $\underline{\text { Potassium }(K) \text { content }}$ & $\underline{\text { Sodium }(\mathrm{Na}) \text { cor }}$ \\
\hline Neutaphos - powder (for mixing with liquid) & $250 \mathrm{mg} /$ packet & $270 \mathrm{mg}$ & $164 \mathrm{mg}$ \\
\hline Neutraphos- $K$ - powder (for mixing with liquid) & $250 \mathrm{mg} /$ packet & 556 & 0 \\
\hline K-Phos Original -uncoated tablet (to mix in liquid, acidifying) & $114 \mathrm{mg} / \mathrm{tablet}$ & 144 & 0 \\
\hline$K$-Phos $M F$ - coated tablet (mixing not required, acidifying) & 126 & 45 & 67 \\
\hline K-Phos \#2 (double strength of K-Phos MF) & 250 & 90 & 133 \\
\hline K-Phos Neutral-tablet (non-acidifying, mixing not required) & 250 & 45 & 298 \\
\hline Phospha-Soda-solution (small doses may be given undiluted) & $127 \mathrm{mg} / \mathrm{ml}$ & 0 & 152 \\
\hline Joulie's solution Prepared by compounding pharmacies & $30 \mathrm{mg} / \mathrm{ml}$ & 0 & $17.5-20$ \\
\hline \multicolumn{4}{|l|}{ Vitamin D and Related Agents } \\
\hline Vitamin D (1 mcg vitamin D = 40 IU) (calciferol; Drisdol®) & \multicolumn{3}{|c|}{$\begin{array}{l}\text { Solution: } 8000 \mathrm{lU} / \mathrm{ml} \\
\text { Tablets: } 25,000 \text { and 50,000 IU }\end{array}$} \\
\hline Dihydrotachysterol (DHT, Hytakerol®) & \multicolumn{3}{|c|}{$\begin{array}{l}\text { Solution: } 0.2 \mathrm{mg} / 5 \mathrm{ml} \\
\text { Tablets: } 0.125,0.2 \text {, and } 0.4 \mathrm{mg}\end{array}$} \\
\hline 1,25 dihydroxyvitamin D calcitriol, Rocaltrol® & \multicolumn{3}{|l|}{$\begin{array}{l}0.25 \text { and } 0.5 \mathrm{mcg} \text { capsules } \\
1 \mathrm{mcg} / \mathrm{ml} \text { solution }\end{array}$} \\
\hline Calcijex® & \multicolumn{3}{|c|}{ Ampules for IV use containing solutions with 1 or $2 \mathrm{mcg} / \mathrm{ml}$ of drug } \\
\hline 1a- hydroxyvitamin D (alfacalcidol) & \multicolumn{3}{|c|}{$\begin{array}{l}0.25,0.5 \text {, and } 1 \mathrm{mcg} \text { capsules } \\
\text { Oral solution (drops): } 2 \mathrm{mcg} / \mathrm{ml} \\
\text { Solution for IV use: } 2 \mathrm{mcg} / \mathrm{ml}\end{array}$} \\
\hline \multicolumn{4}{|l|}{ Vitamin D analogues: } \\
\hline paricalcitol (Zemplar®) & \multicolumn{3}{|l|}{1,2 , and 4 mcg capsules } \\
\hline doxercalciferol (Hectoral $\left.{ }^{\circledR}\right)$ & \multicolumn{3}{|c|}{$0.5,1$, and 2.5 mcg capsules } \\
\hline
\end{tabular}


Table 2

Dose adjustments based on monitoring

\begin{tabular}{|c|c|}
\hline Clinical Finding & Potential Dose Adjustments \\
\hline & Safety Considerations \\
\hline Hypercalciuria, normal serum calcium & $\downarrow$ calcitriol, and/or $\uparrow$ phosphate \\
\hline Hypercalcemia & $\downarrow$ calcitriol; discontinue both medications if moderate to severe hypercalcemia \\
\hline \multirow[t]{2}{*}{ 个PTH } & $\uparrow$ calcitriol, and/or $\downarrow$ phosphate; consider cinacalcet in adults \\
\hline & Efficacy Considerations \\
\hline $\begin{array}{l}\text { Lack of radiographic response or Inappropriate } \\
\text { growth deceleration }\end{array}$ & $\uparrow$ calcitriol or phosphate, as tolerated and within weight based guidelines \\
\hline Continued osteomalacic pain & $\uparrow$ calcitriol or phosphate, as tolerated within guidelines \\
\hline Hypophosphatemia & $\begin{array}{l}\text { THIS IS GENERALLY NOT AN INDICATION TO INCREASE PHOSPHATE DOSE, } \\
\text { AS HYPERPARATHYROIDISM OFTEN ENSUES }\end{array}$ \\
\hline
\end{tabular}

